\title{
On Human Dignity as a Foundation for the Right to Privacy
}

\author{
Luciano Floridi ${ }^{1}$
}

Published online: 26 April 2016

(C) Springer Science+Business Media Dordrecht 2016

On 14 April 2016, the European Parliament approved the General Data Protection Regulation (GDPR). The expression "human dignity" appears in Article 88, which indicates that rules

"shall include suitable and specific measures to safeguard the data subject's human dignity [my italics], legitimate interests and fundamental rights, with particular regard to the transparency of processing, the transfer of personal data within a group of undertakings, or a group of enterprises engaged in a joint economic activity and monitoring systems at the work place" Council of the European Union (2016).

The text just quoted contains two assumptions: that the data subject must be a human person, whose dignity is safeguarded (a legal person could not enjoy human dignity); and that human dignity is different from "legitimate interests and fundamental rights". Both are correct, and the second assumption is indicative. Despite its almost invisible presence in the GDPR, human dignity is the fundamental concept that provides the framework within which one needs to interpret what the GDPR - and more generally European culture and jurisdiction (Lynskey (2015)) — understand by informational privacy (henceforth only privacy). This is coherent with the role played by the concept both in the 1948 Universal Declaration of Human Rights (Preamble and Article 1) and in the EU Charter of Fundamental Rights. ${ }^{1}$ As the European Data Protection Supervisor (EDPS) has stressed:

\footnotetext{
${ }^{1}$ For more information see http://fra.europa.eu/en/charterpedia/article/1-human-dignity
}

Luciano Floridi

luciano.floridi@oii.ox.ac.uk

1 Oxford Internet Institute, University of Oxford, 1 St Giles, Oxford OX1 3JS, UK 
"[...] better respect for, and the safeguarding of, human dignity could be the counterweight to the pervasive surveillance and asymmetry of power which now confronts the individual. It should be at the heart of a new digital ethics. [...] Privacy is an integral part of human dignity, and the right to data protection was originally conceived in the 1970 s and 80 s as a way of compensating the potential for the erosion of privacy and dignity through large scale personal data processing." European Data Protection Supervisor (2015)

I agree. The protection of privacy should be based directly on the protection of human dignity, not indirectly, through other rights such as that to property or to freedom of expression. In other words, privacy should be grafted as a first-order branch to the trunk of human dignity, not to some of its branches, as if it were a second-order right.

I have been defending the same point for some time (Floridi $(2005,2006,2013)$ ), by arguing in favour of the interpretation of the protection of privacy as protection of personal identity: "my" in "my data" is not the same "my" as in "my car", it is the same "my" as in "my hand", because personal information plays a constitutive role of who I am and can become. So the challenge-for those, like me, who agree with the previous analysis - is not that privacy cannot be made dependent on human dignity, for the logical connection appears to be solid. It is rather that this may be just a way of shifting the problem, kicking the privacy can down the road of human dignity. For unless one explains convincingly what human dignity may mean in the twentyfirst century, it remains obscure and questionable exactly which interpretation of human dignity may provide the foundation for privacy (as well as all other human rights), and hence why. As Galileo remarks (see now Galilei (1967)), we may be running the risk of explaining ignotum per ignotius, what is unknown (privacy) by what is even more unknown (human dignity). We clearly need to make a step forward. Such a step requires realising that what is at stake is nothing less than a philosophical anthropology in line with our time, that is, a philosophical understanding of human nature that is adequate to the digital age and our information societies (Floridi (2011)).

Depending on what position one takes with respect to a philosophical anthropology, there follow different views about human dignity, and hence different ways of defending privacy on its basis. This is some progress, but it is still insufficient. What we also need to acknowledge is that philosophical anthropologies, although they may differ from each other significantly, all share the same strategy: they provide an interpretation of human dignity by relying on the defence of some kind of human exceptionalism. That is, whatever human dignity is, its interpretation is the outcome of a specific philosophical anthropology that sees humanity as essentially different from any other species (and indeed any entity in the universe), and in a way that deserves special consideration and respect. So the complete line of reasoning, pruned of its inessential features, is that privacy is to be protected because of human dignity, which is to be protected because of human exceptionalism, which is to be explained and defended by a specific philosophical anthropology, which is in its turn in need of a justification.

When people disagree on privacy and on what human dignity means, one can now see that they really disagree about which philosophical anthropology should be endorsed. This is not surprising. There are four main philosophical anthropologies that have contributed to the debate on human exceptionalism (Lebech (2004)), at least in 
Western philosophy. In Greek and Roman philosophy, and especially in Aristotle and Cicero, human exceptionalism is grounded on humanity's natural and unique ability of exercising virtuous control over itself (e.g. passions) and its environment (e.g. animals). In Christian philosophy, and especially in Thomas Aquinas, human exceptionalism is grounded on humanity's divine creation and existence in the image and likeness of God. In modern philosophy, and especially after the Enlightenment and Kant, human exceptionalism is grounded on humanity's rational autonomy and the ability of selfdetermination. And in post-modernity, human exceptionalism is grounded on humanity's social recognition of each other's value. The problem with these four philosophical anthropologies is that they are all anthropocentric. Even Christianity considers God as exclusively focused on human affairs. But as I have argued elsewhere (Floridi (2014)), Copernicus, Darwin, Freud, and Turing have each undermined once and for all such an anthropocentric approach to human exceptionalism. We are not at the centre of the cosmos, of the biological kingdom, of the space of reason, or of the infosphere. So, if we are special, we cannot be so because of such old "centralities". If human exceptionalism is still defensible, it is probably only in an "eccentric" version, one that places our special role in the universe at the periphery. "Special" will have to mean "strange" (extraneous to the normal course of nature), rather than "superior".

Such an "eccentric" view of human special role in the universe is not unprecedented. The ethics of care is based on the decentralisation of the agent in favour of the patient (receiver) of the moral actions. The gardener, the nurse, the teacher, the parent, the friend, the politician, the civil servant, the medical doctor, the lawyer, the team player, the colleague, the person behind the cashier or in the shop... when they act morally they do so by placing the receivers of their actions at the centre of the interactions, and themselves at their peripheral service. It is the altruistic, patient-oriented (as opposed to agent-oriented) approach advocated in medical ethics, in environmental ethics, in bioethics, in business ethics, and, in my research, in information ethics. Whenever you catch philosophers talking about "listening" rather than "seeing" you know that the shift in perspective might have occurred.

Clearly, a decentralised approach to human exceptionalism is viable. So a defence of human dignity in terms of human exceptionalism is still plausible. But then, what does human dignity mean, from an "anthropo-eccentric" perspective? And can an "anthropo-eccentric" interpretation of human dignity really support the protection of privacy directly, without the mediation of other rights?

The suggestion I would like to put forward is that human dignity, from an anthropoeccentric yet still exceptionalist perspective, lies in a minus not in a plus. We are the incomplete species that wants, that misses, that asks questions, that has doubts, that worries or rejoices about the future and regrets or feels nostalgia or saudade about the past, that can see the other side of the coin, that is in charge of its life, at least partially, that does not live here and now, like all other animals, but detached, in semantic spaces that it designs for its own consumption, in order to give meaning to reality (hopes and fears, passions, memories and expectations, gossip, customs and laws, languages, traditions, religions, social structures, scientific knowledge, and so forth), and yet not too detached, for it is not insane.

This "eccentric" view too is not entirely new. Pico della Mirandola, in his famous Oration on the Dignity of Man (1486; see now Pico della Mirandola (2012)) offers a perspective that seems to me to be close. The Oration has been described as the 
manifesto of the Renaissance. Its message, once refined from rhetorical artifices, is that human dignity consists in its being a work-in-progress, an open software we may say today, or an unwritten text, in less contemporary language. We are not at the top of the chain of being, because we do not belong to it, and there is no room for us in it. We are neither angels nor brutes (or robots), because we are capable of becoming either.

Updating the Oration, one may say that we are outliers, like an "apax legomenon" (i.e., a term of which only one instance of use is recorded in a text) in Galileo's book of nature, which he famously described as written in mathematical symbols. An apax legomenon is an entirely natural phenomenon, and yet it is exceptional. Our exceptionalism lies in a special and perhaps irreproducible way of being successfully dysfunctional. We are nature's beautiful glitch, in a universe-system that has fortuitously and probably uniquely generated a form of life most unlikely to occur again, and certainly anomalous and strange. We are endowed with consciousness, intelligence, mental life, and self-determination. We clearly should not be here. We are the lucky winners of a once in a universe-life time lottery ticket.

I do not know a word that exactly captures this anti-heroic interpretation of human exceptionalism, so let me appropriate one that comes close to doing a good job: polytropos. It is the Greek word used by Homer to describe Odysseus in the very first line of the Odyssey: polytropon, "a man of twists and turns", in Robert Fagles' beautiful translation. Of course "poly" simply means "many", but "tropon" has itself a variety of meanings: "way" as in "manner" or "mode"-thus describing someone who is clever, tricky, able to understand and exploit an opportunity, find a solution, get out of a difficult predicament—but also "way" as in "journey" or "travel", thus describing someone who has seen the world, may be street-wise, much-travelled and muchwandering. It is the word (trope) that we use to refer to commonly recurring literary and rhetorical devices, or clichés in creative works, once clever, now well-trodden motifs. It is the same word used in The Hymn to Hermes to describe the god, inventor of fire and bringer of dreams, emissary and messenger of the gods and intercessor between them and us, protector of literature and poetry, invention and trade, but above all polytropos, cunning, and indefatigable traveller. Even in the New Testament, God himself is said to talk to us polytropõs "in many ways" or "in various modes" (Hebrews 1.1). Such a semantic richness comes handy for our present task. For our polytropic predicament, this special mix of old cleverness and new openness, is what makes us exceptional in many smart and wandering ways. Such an eccentric place in the universe clarifies both our dignity, as a source of rights, and our destiny, as a source of duties, in the following sense.

As travellers, we are in the hands of our hosts: the others, nature, the physical world, but also society, culture, the world we build, not just the world we find. None of us is ever at the centre, we endlessly travel from centre to centre. And so we should enjoy the right to protection and hospitality that welcomes guests. Each of us, as a beautiful glitch, is a fragile and very pliable entity, whose life is essentially made of information. Our dignity rests in being able to be the masters of our own journeys, and keep our identities and our choices open. Any technology or policy that tends to fix and mould such openness risks dehumanising us, not unlike Circe's guests, who are prevented from leaving her island. Thus, human dignity, understood in terms of polytropy, provides the anthropo-eccentric ground for the right to privacy and individual control over our own constitutive information. Most of our selves, understood as narratives, are 
written by other authors, what is left to the each of us to contribute must be carefully protected and fostered.

And still as travellers, we have the duties that any guest should exercise when welcomed to a place: care and respect for the other, any other, human, animate, or inanimate. Such stewardship towards the world we inherit from past generations and leave to future ones is the counterpart of our right to privacy. It is the hallmark of being human that we can care beyond our needs and drives. A private life complements a caring life. This leads me to two last comments.

First, once compared to the other four philosophical anthropologies, it seems clear that only an anthropo-eccentric approach can provide an interpretation of human exceptionalism that is sufficiently robust to justify the protection of privacy via the concept of human dignity. Consider what would happen when privacy is not respected. This would mean that human dignity is violated, but what exactly would be such violation? In Greek and Roman philosophy, it would have to be equivalent to some kind of harm to humanity's natural and unique ability to exercise virtuous control over itself and its environment. This seems to be hardly the case. In Christian philosophy, it would have to be equivalent to some kind of harm to humanity's divine creation and existence in the image and likeness of God. This is clearly irrelevant. Indeed Augustine speaks quite firmly against privacy exactly for the opposite reason: good persons have nothing to hide, to God or to others. In modern philosophy, it would have to be equivalent to some kind of harm to humanity's rational autonomy and the ability of self-determination. This comes much closer to being convincing, insofar as a perceived lack of privacy may shape choices and behaviours and hence constrain autonomy. But it says nothing about undisclosed (and hence unperceived) breaches of privacy. And indeed autonomy would still be possible in a world without any privacy, precisely in the sense in which Augustine saw no need for privacy in a universe in which no person could hide anything from an omniscient God. In post-modern philosophy, the need for mutual recognition may actually encourage a lack of privacy and explain why we care so little about how much we share online. Only within a philosophy of information that sees human nature as constituted by informational patterns do breaches of privacy have an ontological impact. If human exceptionalism is anthropo-eccentrically based on the peculiar status of human beings as informational organisms intrinsically lacking a permanent balance but constantly becoming themselves, like informational works in progress, then a complete lack of privacy is indeed dehumanising. It would impede that detachment that makes human life flourish. It would bridge that special gap between the world and the mind that allows the latter to build a self and a sense of the world. It would remove the grain of sand that makes the pearl possible. It would pin down an open life onto the mounting board of a profile.

Second, if the analysis is kept at a level where humanity confronts the world, then inevitably human dignity is discussed as humanity's dignity, not mine or yours, and the same happens with human destiny. But if we adopt a more finely grained perspective, and look at individual persons as open projects, then an important feature emerges. If Alice and Bob meet, and each of them places herself or himself at the periphery of their interactions, centralising the other, this dialectic seems endless and pointless. A bit like two well-mannered people who, meeting in front of a restaurant, insist that the other should enter first. Both may remain outside. Such a sterile stalemate is a risk, but not an inevitable one, because the de-centralization of the agents may fruitfully lead to the 
centralization of their relation. Then, it is not the wife or the husband who is at the centre of the ethical discourse, but their marriage, to which they both contribute "eccentrically". It is not one of the friends at the centre, but their friendship. Not one party, but politics. Not any of us, but our society. The two people outside the restaurant may enter together, as a couple. This, in terms of privacy, is good news. Because the respect of each other's personal information does not have to lead to a world of solipsistic lives, it can be the basis of a society that promotes the value of relations as something to which those who are related wilfully and fruitfully contribute, from their periphery.

\section{References}

Council of the European Union (2016), 'Position of the Council at First Reading with a View to the Adoption of a Regulation of the European Parliament and of the Council on the Protection of Natural Persons with Regard to the Processing of Personal Data and on the Free Movement of Such Data, and Repealing Directive 95/46/Ec (General Data Protection Regulation) St 54192016 Init - 2012/011 (Olp)'.

European Data Protection Supervisor (2015), 'Opinion 4/2015 Towards a New Digital Ethics Data, Dignity and Technology'

Floridi, L. (2005). The ontological interpretation of informational privacy. Ethics and Information Technology, 7(4), 185-200.

Floridi, L. (2006). Four challenges for a theory of informational privacy. Ethics and Information Technology, $8(3), 109-119$.

Floridi, L. (2011). A Defence of Constructionism: Philosophy as Conceptual Engineering. Metaphilosophy, 42(3), 282-304.

Floridi, L. (2013). The ethics of information. Oxford: Oxford University Press.

Floridi, L. (2014). The fourth revolution - how the infosphere is reshaping human reality. Oxford: Oxford University Press.

Galilei, G. (1967). Dialogue concerning the two chief world systems-ptolemaic \& copernican (2nd ed.). Berkeley: University of California Press.

Lebech, M. (2004). What is human dignity? Maynooth Philosophical Papers, 392, 59-69.

Lynskey, O. (2015). The foundations of EU data protection law. Oxford: Oxford University Press.

Pico della Mirandola, G. (2012). Oration on the dignity of man: a new translation and commentary. Cambridge: Cambridge University Press. 